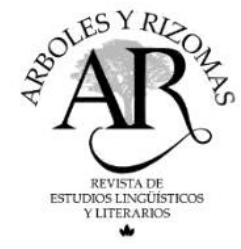

Árboles y Rizomas Vol. III, No 2 (Julio-Diciembre, 2021): 85-103

Universidad de Santiago de Chile, ISSN 0719-9805

https://doi.org/10.35588/ayr.v3i2.5043

\title{
Representaciones del movimiento social contra la dictadura chilena en Tengo Miedo Torero ${ }^{1}$
}

\author{
Representations of the social movement against the Chilean dictatorship in \\ Tengo Miedo Torero
}

\author{
Cristóbal Allende Pino
}

\begin{abstract}
Resumen
El presente artículo explora las representaciones sobre el movimiento social contra la dictadura chilena en la obra Tengo Miedo Torero (2001) de Pedro Lemebel. Considerando las potencialidades que tiene el análisis de las obras de arte para el abordaje de fenómenos sociales y la progresiva inclusión de la dimensión emocional en el estudio de los movimientos sociales, el análisis muestra que la novela de Lemebel integra representaciones del movimiento social contra la dictadura cercanas a la Nueva Historia Social, que incluye la descripción de escenarios de marginalidad, cesantía, juventud, represión, entre otras representaciones. Por otro lado, las emociones integradas en la narrativa de Lemebel (indiferencia, miedo, valentía) permiten abordar en mayor profundidad la etapa dictatorial chilena, explorando en dichos constructos emocionales que tradicionalmente las corrientes historiográficas no atienden.
\end{abstract}

Palabras claves: Pedro Lemebel, Tengo Miedo Torero, dictadura chilena, movimiento social, emociones

\begin{abstract}
This article explores the representations of the social movement against the Chilean dictatorship in Pedro Lemebel's novel Tengo Miedo Torero (2001). Considering the potentialities of analyzing works of art to approach social phenomena and the increasing importance of the emotional dimension in the study of social movements, the analysis shows that the novel integrates representations of the social movement against the dictatorship that are coherent with the New Social History. These representations manage to highlight peripherical settings, unemployment, young people, and repression, among others. Furthermore, the emotions in Lemebel's narrative (indifference, fear, courage) allow to tackle in depth the Chilean dictatorship by exploring these emotional constructs not traditionally attended by historiography.
\end{abstract}

Keywords: Pedro Lemebel, Tengo Miedo Torero, Chilean dictatorship, social movement, emotions.

\footnotetext{
${ }^{1}$ Trabajo realizado en el contexto de la asignatura "Movimientos sociales y manifestaciones artísticas y literarias en el Cono Sur" del Magíster en Arte, Pensamiento y Cultura Latinoamericanos, Instituto de Estudios Avanzados, Universidad de Santiago de Chile.

${ }^{2}$ Sociólogo, Universidad de Chile. Integrante del Núcleo de Sociología del Arte y de las Prácticas Culturales, Universidad de Chile. Correo: cristobal.allende@ug.uchile.cl. ORCID ID: https://orcid.org/0000-0001-9869-647X
} 


\section{Introducción}

La presente investigación explora las representaciones acerca del movimiento social contra la dictadura chilena, en la obra Tengo Miedo Torero (2001), de Pedro Lemebel. En un primer apartado se exponen dos formas de entender la salida de la dictadura: desde la historia oficial y desde la Nueva Historia Social. El segundo apartado busca exponer la situación de las culturas y las artes en el contexto dictatorial, momento en el cual inicia su trabajo artístico Pedro Lemebel. En un tercer apartado se aborda la relación entre arte y sociedad, profundizando en las potencialidades que tiene el análisis de las obras artísticas para la investigación social. Como subapartado, se propone una revisión de la literatura académica que ha analizado y releído la novela Tengo Miedo Torero. En el cuarto apartado se exponen los resultados del análisis, desglosados en dos subapartados: el primero refiere a las representaciones acerca del movimiento social presentes en la obra de Lemebel, y el segundo enfatiza el aspecto emocional de estas representaciones. El quinto apartado entrega las conclusiones del análisis, además de integrar algunas proyecciones investigativas.

\section{Entre el pacto transicional y la resistencia: dos formas de comprender la salida de la dictadura chilena}

Generalmente, la historia tradicional sobre la Dictadura Chilena (1973-1989) tiende a caracterizar el fin de este periodo desde los acuerdos entre los partidos políticos (Garretón, 1993), o desde los procesos institucionales que dieron cabida al plebiscito y posterior etapa transicional (Otano, 1995). En ese contexto, se destaca el surgimiento de la Concertación de Partidos Por el No, coalición que aglutinaba a gran parte de los partidos políticos opositores al régimen dictatorial y que posteriormente gobernarían bajo el nombre de Concertación de Partidos por la Democracia . Será el mismo Ricardo Lagos, político emblemático de esta coalición y presidente de la República entre el 2000 y 2006, quien dirá:

La transición es obra del pueblo de Chile, de sus 15 millones de habitantes. Sin embargo, ha sido la conducción de esta coalición lo que ha permitido al país avanzar en los distintos campos y lo que genera ahora desafíos futuros. (Lagos, 2008, p. 39)

Frente a este protagonismo historiográfico otorgado a los partidos políticos y al ámbito institucional, ha sido la Nueva Historia Social la encargada de explorar “...la memoria -privada pero colectiva- de las mayorías ciudadanas que han estado sujetas, por décadas y aún siglos, a la exclusión, la pobreza, el empleo precario y la represión" (Grez y Salazar, 1999, p. 35). En ese sentido, no es posible entender el fin del periodo dictatorial sin reconocer la presencia de los movimientos de trabajadores y pobladoras, las juventudes, y un sinfín de organizaciones que protagonizaron la resistencia a la dictadura de Augusto Pinochet durante los años ochenta.

En dicho contexto, el punto más álgido de la movilización en contra de la dictadura corresponde a las Jornadas Nacionales de Protesta, ocurrida la primera el 11 de mayo de 1983 y realizándose 22 de ellas hasta 1986. Según De la Maza y Garcés (1985), “...la protesta constituye una doble negación del orden dictatorial, por cuanto, por una parte, pone en relación conflictiva a 
la sociedad con el Estado y, por otra, restituye los lazos entre los diversos sectores sociales..." (p. 19). Desde una visión antropológica (Bravo, 2019), la protesta durante estas jornadas incluía cortes de calles, ausencia de los espacios educativos y de trabajo, barricadas y enfrentamientos con la policía; además, elementos como el ruido (a través de los cacerolazos), el fuego y las piedras se transforman en símbolos etnográficamente relevantes de estas jornadas. Por otro lado, será particularmente en las poblaciones donde las manifestaciones se harán más amplias y masivas (Garcés, 2013), en tanto los jóvenes “descubrieron que podían establecer mayor control sobre sus acciones o enfrentar en mejores condiciones a la policía y a los militares, en sus propios territorios" (Garcés, 2013, p. 88).

Gracias a esta sostenida oposición popular expresada en las calles durante tres años fue posible el rearme de los referentes políticos y los inicios de la transición pactada: "Sólo dos semanas después de la tercera protesta, nació el pacto de oposición llamado Alianza Democrática (AD), base de la coalición gobernante en Chile hasta marzo de 2010" (Bravo, 2012, p. 106). Aun así, y a pesar del protagonismo de los movimientos sociales en este contexto, la salida dictatorial y la posterior transición democrática excluyó la participación popular, optando finalmente por el acuerdo entre los partidos y proyectando en democracia el modelo socioeconómico instaurado en la Constitución de 1980 (Rovira, 2007).

\section{Resistencias culturales y artísticas a la dictadura}

En relación con el campo cultural y artístico, este también fue un espacio reprimido por parte del régimen dictatorial militar. Con la idea de reducir lo más posible las expresiones artísticas populares y particularmente las vinculadas a las ideas de izquierda, la dictadura se encargó de quemar libros, realizar detenciones y torturas a artistas emblemáticos de aquel tiempo, y exiliar a gran parte de los referentes culturales de la época, momento histórico referido como "apagón cultural" (Donoso, 2013).

Aun así, tanto desde el exilio como desde el territorio nacional, artistas y agentes culturales lograron progresivamente eludir los mecanismos de censura y dar a conocer su arte, muchas veces comprometido con la resistencia a la represión dictatorial. Tal vez el caso más reconocido es el trabajo realizado por el Colectivo de Acciones de Arte (CADA), organización formada en 1979 por artistas como Diamela Eltit, Lotty Rosenfeld, Juan Castillo, Fernando Balcells y Raúl Zurita (Vega, 2013). Mediante intervenciones en el espacio público, esta agrupación “intentó crear formas de resistencia que les permitiesen expresar su posicionamiento político contrario al régimen" (Vega, 2013, p. 46) . $^{3}$

En ese contexto, el mismo Pedro Lemebel, dentro de su fructífero repertorio de producción artística, que abarca desde el periodo dictatorial hasta la postdictadura, conformó junto a Francisco Casas el colectivo "Las Yeguas del Apocalipsis", el año 1988. Desde ese entonces, "activaron una serie de intervenciones y posicionamientos artísticos-políticos, en distintas ciudades del país, hasta

\footnotetext{
${ }^{3}$ Para una revisión sobre la producción artístico cultural en este contexto, se sugiere el trabajo de Isabel Jara (2020), quien reflexiona en torno a las investigaciones previas sobre la acción cultural en la dictadura nacional.
} 
el año 1993 en el contexto de la 'transición democrática' chilena” (Yeguas del Apocalipsis, 2018) ${ }^{4}$. El ejercicio performático de Las Yeguas del Apocalipsis planteaba un diálogo crítico con el campo de la memoria post dictatorial (Sandoval, 2018), en tanto se construía desde una diferencia que "se expresaba en cuerpos disidentes, maricas, sexualmente ambiguos o indefinidos, travestidos y mutables que, además, recuperaban espacios públicos para transformarlos en nuevos territorios simbólicos donde discutir y procesar públicamente y de otros modos las experiencias de violencia" (Sandoval, 2018, p. 11).

Justamente, este trabajo explora una de las obras de Pedro Lemebel, su única novela Tengo Miedo Torero, publicada el año 2001, donde se indaga en las representaciones sobre el movimiento social contra la dictadura. Se sostiene como hipótesis que, debido a la posición crítica de Lemebel en el campo artístico chileno, las representaciones sobre el movimiento social contra la dictadura en Tengo Miedo Torero entregan una visión renovada de este, alejada de la historia tradicional y más cercana a la Nueva Historia Social, aunque agregando otros elementos propios de la posición de Lemebel como activista performático, desde la disidencia sexual y la marginalidad.

\section{Sobre la relación entre arte y sociedad}

El entendimiento de la relación entre el arte y la sociedad ha seguido distintos derroteros, particularmente desde comienzos del siglo XX (Heinich, 2002). A pesar de que en este subcampo de la sociología ha primado últimamente la comprensión del fenómeno artístico desde las lógicas de su producción, recepción y mediación, a través de conceptos como mundo del arte (Becker, 2008) o campo artístico (Bourdieu, 1990) la posibilidad de entender las sociedades desde la observación de las obras de arte ha sido un campo de análisis interesante, desde al menos comienzos del siglo XX.

Sobre este vínculo entre las obras de arte y el mundo social, Calhoun y Wieviorka (2013) señalan:

Para comprender hoy en día el terrorismo ¿acaso no vale más leer a Dostoievski o a Camus que la prosa de los investigadores, por más especializados que se digan? Para comprender lo que fue la Gran Depresión en el campo estadounidense ¿no es mejor leer a Steinbeck. (pp. 53-54)

La idea es entender el cruce de fronteras (Trejo y Waldman, 2018) entre el oficio del escritor, que muchas veces tiene que generar un proceso de investigación social exhaustivo para realizar sus obras, y el trabajo del investigador social, en donde lo narrativo ocupa lugar tanto en lo metodológico como en la forma de exponer sus hallazgos.

Por otro lado, Gisèle Sapiro (2016) señala que el entendimiento de la obra no se debe reducir solamente a su función de representación, bajo la idea del espejo. Por el contrario,

\footnotetext{
${ }^{4}$ Página web que expone una selección del Archivo Yeguas del Apocalipsis (AYA), construido en el marco del proyecto FONDART “Archivo Yeguas del Apocalipsis. Registros, voces y relatos” (2015-2018) (Fernanda Carvajal y Alejandro de la Fuente).
} 
...la literatura oscila entre representación y simbolización. Del lado de la representación, se tiende a postular la transparencia del lenguaje, la primacía del significado, y a recurrir más bien a la metonimia, mientras que, del lado de la función de la simbolización, el lenguaje es opaco, significa, es el reino de la metáfora y de la atención puesta en forma. (Sapiro, 2016, pp. 85-86)

Entonces, la literatura se entiende alejada de un rol solamente pasivo de reflejo, para ser partícipe de la construcción de los imaginarios colectivos de una sociedad. Este protagonismo es aún más latente si se considera el periodo dictatorial iniciado en 1973. Como señala Garretón (2014), durante el régimen militar se cerraron varias carreras de ciencias sociales en las universidades, reduciendo drásticamente el financiamiento estatal a la investigación. Frente a este debilitamiento del análisis y reflexión sistemática del contexto nacional, las obras literarias pueden ser una profunda fuente de conocimiento sobre el periodo, sobre todo si el escritor fue protagonista y militante de la resistencia a la dictadura, como es el caso de Pedro Lemebel.

\section{Acerca de la novela Tengo Miedo Torero (2001)}

Con respecto a la historia de la novela, una crítica publicada el año del lanzamiento del libro, sintetiza la trama de la siguiente forma:

Es 1986 y en las calles de Santiago las protestas y las barricadas mantienen en vilo a sus ciudadanos. La radio Cooperativa no para de informar sobre los últimos disturbios. En medio de esa batahola, la Loca del Frente, así le llama a este homosexual cuarentón, ex |travesti, con poco pelo y sin dientes, que vive su vida ajena a contingencias políticas, escuchando canciones romanticonas como "Tengo miedo, torero, tengo miedo que en la tarde tu risa flote", de Sara Montiel. Personaje grotesco y realista, sacado con exacta fidelidad de la marginalidad santiaguina, que ve su vida trastornada cuando conoce a Carlos, joven frentista que prepara el atentado contra Pinochet en el Cajón del Maipo, enamorándose perdidamente de él. (Aguirre, 2001, s/p)

Además, la historia entre Carlos y La loca del Frente tiene como contrapunto, a lo largo de la novela, los diálogos y pensamientos de Augusto Pinochet junto con su esposa Lucía:

En Tengo Miedo Torero, el dictador Augusto, también referido, a veces, como Pinocho, sufre bajo la dictadura doméstica de su mujer, Lucía, personaje que le molesta todo el tiempo con su hablar ininterrumpido y su preocupación por la apariencia física y la moda. (Da Silva, 2012, p. 196)

La obra se puede leer, claramente, “...dentro de las novelas de la dictadura (...) aunque sin duda también debe mucho a los procedimientos que en la postmodernidad plantea la Nueva Novela Histórica al adoptar la actitud irreverente y carnavalesca" (Ruiz, 2019, p. 86).

En concordancia con la extendida recepción que esta obra ha tenido en la sociedad chilena y también a nivel latinoamericano, son variados los artículos y ensayos que han reinterpretado y releído esta novela. Se destaca en ellos el lenguaje utilizado por Lemebel en la obra, el cual "desterritorializa el amor heterosexual y los relatos maestros de la Historia de Chile para dar cabida 
a los hijos mestizos, a los huachos y a aquellos cuya cara o voz no coincide con su cuerpo" (López, 2005, p. 128). Según Almenara (2016), este "lenguaje travesti" se opone tanto a la masculinidad hegemónica reflejada en la imagen del dictador Augusto Pinochet como también a la del militante de izquierda "quien supone que existe una única forma de resistir y combatir la opresión de la dictadura" (p. 87).

Esta subversión en el lenguaje trae consigo un contra discurso opositor a dos regímenes de origen patriarcal: el dictatorial y el del guerrillero (Barrera, 2016). Esta toma de posición, según la literatura que aborda la novela de Lemebel, se expresa desde tres configuraciones artísticas: el barroco y neobarroco ${ }^{5}$, el Camp ${ }^{6}$, y el Kitsch ${ }^{7}$ (Castro, 2021; Hueso, 2013; Neyret, 2007; Barrera, 2016). De esta forma, el neobarroco en la prosa de Lemebel muestra que es posible "la estructuración de un lenguaje diferente al reproducido por los poderes fácticos de la dictadura" (Castro, 2021, pág. 173), lenguaje que además funciona como soporte para la configuración Camp de las intervenciones del personaje La Loca del Frente, "marcadas por la incongruencia, la teatralidad y el sentido del humor" (Hueso, 2013, pág. 399). Por otro lado, el Kitsch, presente en las "líricas pasadas de moda" (Lemebel, 2001, pág. 10) cantadas por el personaje principal y que aparecen también como marcas textuales de la novela, se terminan politizando en la novela de Lemebel (Neyret, 2007). La Loca del Frente

...deja atrás la frivolidad del kitsch, para transformarlo en una herramienta de lucha no solo por la libertad de su país, sino que también para abrir paso a todas aquellas voces que han sido silenciadas en la historia del sometimiento en América Latina. (Barrera, 2016, p. 56)

Bajo estas configuraciones artísticas y literarias, el cuerpo y la performance adoptan también un protagonismo relevante en la novela de Lemebel, marcados también por la sexualidad y el travestismo (Pinto, 2016; Manickam, 2010; Pérez, 2019). La diferencia sexual se presenta como "un desafío a esta sociedad" (Manickam, 2010, p. 42), la cual está marcada tanto por el régimen dictatorial como por la dominación heteropatriarcal. Además, como señala Pinto (2016):

\footnotetext{
${ }^{5}$ Según Sarduy, el espacio del barroco es el de la "superabundancia y el desperdicio". Contrariamente al lenguaje comunicativo, económico, austero, reducido a su funcionalidad - servir de vehículo a una información -, el lenguaje barroco se complace en el suplemento, en la demasía" (Sarduy, 1974, p. 100). Por otro lado, según Alvarado-Borgoño (2016) el neobarroco corresponde al "modo específico en que aún hoy la exacerbación de la forma, propia del barroco, se expresa en un orden del desbarajuste, sin que ello sea un juego de palabras, es decir, se expresa en una lógica que no identifica lo racional con lo real, sino que vive en el intento de la representación y de la representación de la representación" (p. 335).

${ }^{6}$ Con respecto al Camp, este se define, según Susan Sontag, como "una concepción del mundo en términos de estilo; pero de un tipo particular de estilo. Es el amor a lo exagerado, lo off, el ser impropio de las cosas" (Sontag, 2005, p. 359).

${ }^{7}$ El Kitsch, aunque difícilmente se puede entregar una definición clara, refiere al arte barato y popular, catalogado desde las elites como un no-arte. Según Moles (2011), el kitsch responde a los principios de inadecuación (remplaza lo puro por lo impuro), de acumulación (frenesí), de percepción sinestésica, que "trata de tomar por asalto la mayor cantidad posible de canales sensoriales" (p. 51), de mediocridad (se opone a la vanguardia y permanece como arte de masas), y el principio de confort (fácil aceptación y espontaneidad perceptiva de la obra).
} 
La figura homosexual y travesti no es sólo un personaje más en la trama novelesca, sino la reconstrucción identitaria de una otredad social y política que, a través del cuerpo marginado, cuerpo ligado a la promiscuidad y brutalidad del sexo; se inscribe en el escenario chileno reclamando su lugar y su voz. (p. 105)

Finalmente, según Ward (2016) la novela de Lemebel se enmarca en un esfuerzo por re(escribir) la historia de esos años, la cual ha sido comúnmente narrada por los vencedores:

Para Lemebel, el proceso de (re)escribir la historia y contarla de una manera que involucra a las voces silenciadas, puede cambiar la política de género y la sexualidad (cambia la política nacional también), algo que intenta hacer en la novela Tengo Miedo Torero. (p. 152)

En esta (re)escritura, Tengo Miedo Torero entrega también una reelaboración de la historia oficial, en donde se presenta un "Santiago destrozado por bombas, llantas quemadas y mucha represión militar" (Da Costa, 2020, p. 100), acercándose así al proyecto de la Nueva Historia Social, como se señalaba anteriormente.

\section{Resultados: movimientos sociales contra la dictadura en Tengo Miedo Torero}

Aunque la discusión teórica sobre movimientos sociales ha sido bastante extensa, particularmente en el contexto latinoamericano (Fry, 2020), para efectos de este trabajo se entenderá el movimiento social desde una definición relativamente amplia y sintética: citando a Paul Almeida (2020), en los movimientos sociales: "las personas comunes y corrientes se unen para lograr una meta en común" (p. 25). La idea de esta amplitud conceptual es poder aproximarse a aspectos de los movimientos sociales generalmente poco atendidos, que al mismo tiempo se acercan a nociones presentes en la obra de Pedro Lemebel, y particularmente en la novela Tengo Miedo Torero ; estos aspectos refieren al cuerpo y las emociones.

En relación con el cuerpo, el mismo Paul Almeida destaca el rol de los jóvenes y estudiantes no solo en movimientos sociales de los que son protagonistas pero también en otros movimientos sociales, en la medida en que "suministran cuerpos para ocupar las primeras filas en manifestaciones públicas y confrontaciones con las autoridades" (Almeida, 2020, p. 228). En ese sentido, como señala Sossa (2013), “...el cuerpo, la presencia física en un movimiento es fundamental, las marchas, las reuniones, dan cuenta de cuerpos que se movilizan y a través de su número exponen su relevancia o su adhesión" (p. 11).

Con respecto a las emociones, la relación entre la acción colectiva, los movimientos sociales y la emocionalidad ha sido atendida de forma importante en el último tiempo (Jasper, 2013; Poma y Gravante, 2017). En definitiva, no se trata de mostrar la presencia e importancia de las emociones en los movimientos sociales y la protesta (cuestión más que evidente), sino más bien de comprender que

...a través del análisis de la dimensión emocional de la protesta se pueden explicar

muchos aspectos de la protesta y de los movimientos sociales, desde la comprensión 
del por qué la gente se moviliza o no, hasta el empoderamiento de los sujetos. (Poma y Gravante, 2015, p. 19)

Con esto en mente, se revisan a continuación las representaciones del movimiento social contra la dictadura en la obra Tengo Miedo Torero (Lemebel, 2001). Se prestará atención a la forma en que Lemebel describe las acciones de protesta y los movimientos sociales, poniendo énfasis en el aspecto emocional que, como vimos, permite explorar en aristas no siempre incluidas en las formas historiográficas clásicas.

\section{Tengo Miedo Torero como material de la Nueva Historia Social}

El relato de Pedro Lemebel, como se señalaba anteriormente, presenta una notoria proximidad con las intención historiográfica de la Nueva Historia Social: una historia de los oprimidos, de ese "medio pelo santiaguino que se rascaba las pulgas entre la cesantía y el cuarto de azúcar que pedían fiado en el almacén" (Lemebel, 2001, p. 11). Lemebel esboza un relato claro de esa marginalidad, que es tanto económica, social, así como también marginación del relato maestro y de la historia oficial. En ese contexto, se reconocen tres tópicos abordados: la resistencia desde los movimientos sociales, la represión desde las fuerzas de orden, y una caracterización de la sociedad chilena de aquellos años.

\section{Resistencias desde los movimientos sociales}

La novela de Lemebel está cruzada constantemente por los hechos de manifestación desplegados en las calles de Santiago durante el año 1986, "Un año marcado a fuego de neumáticos humeando en las calles de Santiago comprimido por el patrullaje. Un Santiago que venía despertando al caceroleo y los relámpagos del apagón; por la cadena suelta al aire, a los cables, al chispazo eléctrico" (Lemebel, 2001, p. 9). Este año (1986) corresponde al momento cúlmine de las jornadas de protesta, las cuales venían desarrollándose desde hace tres años (Bravo, 2019). En uno de los tránsitos de la Loca del Frente por el Paseo Ahumada se narra lo siguiente: "El suelo estaba regado de panfletos llamando a protestar en septiembre: 1986 -AÑO-DE-LA-LIBERTAD. ESTE-AÑOCAE. PINOCHO, SE-TE-ACABÓ-LA-FIESTA. Eran algunas consignas que se leían en los papeles escritos con tinta roja" (Lemebel, 2001, p. 155).

La novela también aborda las acciones realizadas por las agrupaciones de familiares de detenidos desaparecidos, compuestas generalmente por mujeres que habían perdido a sus cercanos:

Pero al llegar cerca de la Catedral, un numeroso grupo de mujeres se juntaban en las escaleras portando las fotos de sus familiares detenidos desaparecidos. JUSTICIAQUEREMOS-JUSTICIA.-LOS-LLEVARON-DETENIDOS-NO-LOS-VIMOSNUNCA-MÁS.-LO-QUE-AHORA-EXIGIMOS-QUE-NOS-DIGAN-DÓNDE-

ESTÁN. Eran las consignas que coreaban las señoras, madres, abuelas, hermanas de toda esa gente que aparecía desteñida en las fotos clavadas en el pecho. (Lemebel, 2001, p. 156) 
O como se señala en páginas anteriores:

Partían el alma los sollozos de esas señoras escarbando piedras, estilando mojadas por el guanaco, preguntando por ellos, golpeando puertas de metal que no se abrían, revolcadas por el chorro del agua frente al Ministerio de Justicia, sujetándose de los postes, con las medias rotas, todas chasconas, agarrándose el pecho para que esa agua negra no les arrebatara la foto prendida a su corazón. (pp. 27-28)

Por otro lado, la historia muestra las operaciones del Frente Patriótico Manuel Rodríguez (FPMR), organización de izquierda originada desde el Partido Comunista bajo la estrategia de "Rebelión Popular de Masas" como oposición a la dictadura (Venegas, 2009). Esta organización, a la cual pertenece clandestinamente Carlos, se adjudicó gran parte de las acciones insurreccionales al régimen (incluyendo el atentado a Pinochet), y que en la novela se exponen desde las transmisiones radiales de Radio Cooperativa": "SERGIO CAMPOS DA LECTURA A LAS NOTICIAS: EL AUTODENOMINADO FRENTE PATRIÓTICO MANUEL RODRÍGUEZ SE ADJUDICÓ EL CORTE DE ENERGÍA QUE DEJÓ SIN LUZ A LA REGIÓN METROPOLITANA" (Lemebel, 2001, p. 27).

\section{Represión por parte de las fuerzas de orden}

La obra aborda las características de la represión ejercida por parte de las fuerzas de orden del régimen, particularmente de dos formas: la represión a la sociedad en general, así como también en experiencias de amedrentamiento sufridas por la protagonista, La Loca del Frente. Con respecto a la primera expresión, se observa la intimidación por parte de la policía en el momento en que es detenido el microbús en que viajaba la Loca del Frente (cargando el paquete encargado por Carlos): "Entonces la micro frenó de improviso y se escuchó un altoparlante: Se ordena a todos los pasajeros de este vehículo bajar de a uno para ser sometidos a una revisión" (Lemebel, 2001, p. 167). El relato anterior da cuenta de la cotidianeidad de la represión, represión que además se ve acrecentada luego del fallido atentado a Pinochet:

Aquella noche de septiembre del 86 fue espesa, un socavón de coyotes aullantes por las avenidas, una ciudad crispada por los numerosos allanamientos, portazos, gritos y balaceras en los barrios populares. El Ejército se tomó Santiago, cortando las rutas de salida. Se montó un cerco armado desde la periferia que se fue cerrando a medida que los militares revisaban autos, casas, poblaciones enteras, formadas en fila toda la noche en las canchas de futbol. (p. 173)

Así también, la protagonista se vio enfrentada a situaciones de represión por parte de las fuerzas de orden, donde además se expresa el régimen de autoridad heteropatriarcal:

\footnotetext{
${ }^{8}$ La cortina de la radio Cooperativa se transformó en “Otro sonido inolvidable para quienes experimentaron estos años de lucha contra la dictadura (...) escuchada por toda una generación en días y noches de protesta” (Bravo, 2019, p. 135). El mismo Lemebel lo destaca en su novela "Tenía que saber algo más de esa noticia, averiguar otros antecedentes más confiables que solo la Radio Cooperativa podía entregar. Por eso giró la perilla buscando en el abanico de músicas y voces el tararán tan reconocido" (Lemebel, 2001, p. 119).
} 
Al agacharse y recoger uno (panfleto), sintió el puntazo de la luma al clavarle las costillas. ¡Bótalo, maricón culiao! Le gritó el paco mirándolo con furia. Y córrete de aquí, anda a mariconear a otro lado, si no querís que te lleve preso. (Lemebel, 2001, p. 155)

\section{Caracterización de la sociedad dictatorial}

A lo largo de la novela se observa igualmente una imagen de la sociedad chilena, particularmente de sus rasgos socioeconómicos marcados por la cesantía, la pobreza y la marginalidad, y que bajo la impronta del neobarroco de Lemebel (Castro, 2021) se representan de una forma estéticamente notable:

Mucha oferta, mucho de todo, hipnosis colectiva de un mercado expuesto para su contemplación, porque muy poca gente compraba, eran contados los que salían de las tiendas cargando un paquete doblemente pesado por la angustia del crédito a plazo. El resto miraba, vitrineaba con las manos en los bolsillos tocándose las monedas para la micro. (Lemebel, 2001, p. 60)

Así también, el relato aborda los contextos de marginalidad, el alcoholismo y la desocupación; por ejemplo, en el momento en que La Loca del Frente va a visitar a sus amigas, La Lupe, la Fabiola y la Rana

...sus únicas hermanas colas que arrendaban un caserón por Recoleta, cerca del Cementerio General, en ese barrio polvoriento lleno de conventillos, pasajes y esquinas con botillerías donde hacían nata los hombres, los jóvenes pobladores que pasaban todo el día borrachos avinagrándose al sol. (p. 75)

Finalmente, a través de los diálogos del Dictador Pinochet con su esposa Lucía, o de las señoras con las que la Loca del Frente se enfrenta en la micro, el relato novelesco aborda también la visión de la sociedad que tienen los sectores acomodados, reaccionarios, y afines a la dictadura:

¿Qué le parece? Estos son los jóvenes de ahora, le murmuró una vieja de moño sentada a su lado. Mire estos zánganos que no tienen respeto y no le dan el asiento a nadie. Lo único que saben es andar tirando piedras y prendiendo barricadas. (Lemebel, 2001, p. 58-59)

O como Pinochet se refiere a los integrantes del FPMR, “...que son puros estudiantes que juegan a ser guerrilleros. Son puros cabros maricones que tiran piedras, cantan canciones de Violeta Parra y leen poesía. Mire qué hombrecitos, chiquillos pollerúos que recitan poemas de amor y metralleta" (p. 133).

Como se observó en los párrafos anteriores, los recursos temáticos y estilísticos de Pedro Lemebel ahondan en esas identidades marginalizadas del régimen: los pobres, cesantes, mujeres y jóvenes, sus opresiones y resistencias, las cuales son excluidas tanto desde las fuerzas dictatoriales como también desde el posterior pacto transicional y desde la historia oficial. Por otro lado, la ciudad juega también un rol importante: las representaciones del centro de la ciudad, los barrios 
populares y los sectores acomodados dan cuenta de la desigualdad económica del país, además de la focalización de la represión por parte de la fuerza policial.

\section{Tengo Miedo Torero, o las emociones del movimiento social contra la dictadura}

Se señalaba anteriormente como las emociones han ido progresivamente ocupando un lugar de interés para la investigación en torno a los movimientos sociales (Poma y Gravante, 2017; Poma y Gravante, 2015 y Jasper, 2013).

En el mismo sentido, la novela Tengo Miedo Torero está cargada de emociones:

La música los envolvió con su tambaleada ranchera, entre la canción y sus pensamientos, la historia política trenzaba emociones, inquietudes del joven frentista al borde del arrojo, ilusiones enamoradas de la loca cerrando los párpados, rezando la letra de esa balada con el pecho apretado, presintiendo cercano el desenlace de una intrépida acción. (Lemebel, 2001, p. 145)

Como se observa en esta cita, la prosa de Lemebel nos entrega muchos otros fragmentos cargados de sentimientos y emocionalidad. Siguiendo entonces con la conexión señalada anteriormente entre lo literario y lo social (Trejo y Waldman, 2018; Sapiro, 2016), observar las emociones que Lemebel impregna a su narración sobre el movimiento social contra la dictadura nos permitiría acceder a una mayor comprensión de este.

De forma preliminar, hay al menos tres elementos iniciales en donde se conecta la emocionalidad, en su sentido amplio, con el movimiento social: el título de la novela, el nombre de la protagonista, y la portada. En primer lugar, el título de la obra (tomado de la canción homónima de Sara Montiel), contrapone dos elementos: el miedo y el torero. El miedo como emoción constante y latente en los sentires de la Loca del Frente; el torero , personificado en Carlos, simbolizando la valentía, el "combate frontal" al que invita el himno del Frente Patriótico Manuel Rodríguez (Ímaz, 2017).

Por otro lado, el nombre "la Loca del Frente" conjuga a la "Loca" como "desviación" (que es sexual y política), y al "Frente" (que no es solo la vereda o casa del frente, sino que también es el Frente Patriótico), como certeza militante, como “...esas instrucciones estrictas que le daba esa cabra chica metida a guerrillera" (Lemebel, 2001, pág. 176). En definitiva, un personaje homosexual, travesti, “...tan enamorada, tan cautiva, tan sonámbula” (pág. 16), en suma, tan cargada de emociones, se ve implicada en una operación fría y calculada, como es el atentado a Pinochet.

Como tercer elemento está la portada, en la Figura 1, comúnmente conocida, que ya se presenta como un ícono popularizado de esta obra. En ella las balas se alinean y se forman en torno a la figura de un corazón en un fondo rojo, símbolo irrefutable de la emocionalidad. 
Figura 1: Portada del libro Tengo Miedo Torero (Memoria Chilena, 2018).

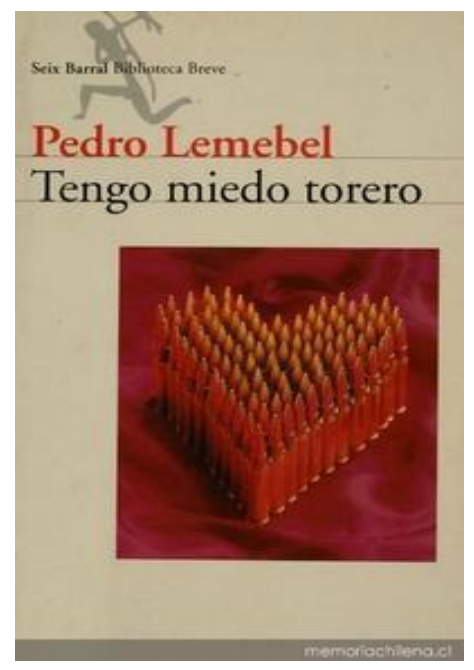

Los tres elementos mencionados (título, personaje y portada), sirven entonces como muestra de la vinculación entre lo emocional y lo político-histórico que propone Lemebel en su novela. Con todo, se profundiza a continuación en las emociones narradas en la obra de Lemebel, en torno al movimiento social contra la dictadura. Particularmente, se observarán tres aspectos emocionales preponderantes en la obra, y que siguen cierta secuencia temporal: primeramente, la indiferencia y el apoliticismo, luego el miedo y el temor, y finalmente la valentía.

\section{Indiferencia y apoliticismo}

El apoliticismo y la indiferencia corresponden a pilares gravitantes del proyecto ideológico de la dictadura militar. Desde la propuesta gremialista "La dictadura estaba decidida a despolitizar a la sociedad chilena, para lo cual rompió el vínculo Estado-partidos-sociedad, mediante el neoliberalismo y la privatización de los servicios sociales y redefinió la participación, entendiéndola como 'social' y no política" (Valdivia, 2016, p. 4). La preocupación de la Loca del Frente por la música del recuerdo (kitsch) por sobre las noticias radiales, es una muestra clara de la imposición de la indiferencia en la población:

Que todos al parque, al cementerio, con sal y limones a resistir las bombas lacrimógenas, y tantos comunicados de prensa que voceaba la radio permanentemente (...) Pero ella no estaba ni ahí con la contingencia política (...) Ella prefería sintonizar los programas del recuerdo: "Al compás del corazón". "Para los que fueron lolos". "Noches de arrabal". (Lemebel, 2001, p. 11)

Sin embargo, esta indiferencia y distancia se expresa luego como un acostumbramiento a las noticias de la radio: “...cuando no encontraba su música preferida, cuando los bombazos cortaban la luz, cuando tenía que ponerle pilas a la radio, la voz de Sergio Campos era un bálsamo protector en esas tinieblas de guerra" (p. 27). 
Por otro lado, el apoliticismo se expresa también en las preocupaciones "banales" de la esposa de Pinochet, Lucía:

...deberías tomar en cuenta la opinión de Gonza que es tan fino y tiene tan buen gusto. Y dice que todo es cosa de estética y color. Que la gente no está descontenta contigo ni con tu gobierno. Que la culpa la tiene el gris de los uniformes, ese color tan depresivo, tan sobrio, tan apagado, tan poco combinable. (p. 30-31)

La estética y el color de las que habla la esposa del dictador son justamente elementos propios del Camp. De esta forma, se observa la transversalidad del proyecto ideológico despolitizante (de preocupaciones superficiales y banales), desde las esferas del poder (Lucía y Augusto) hasta las población marginalizada.

\section{Miedo y temor}

"...la ciudad fuera del auto era una cobra grisácea ondulando en rostros también descoloridos por el susto cotidiano a la dictadura" (Lemebel, 2001, p. 137).

El miedo y el temor se desplegarán constantemente en la novela, tanto en la relación que tiene La Loca del Frente con Carlos, así como también en torno a los acontecimientos históricos de la Dictadura. Por otro lado, tanto miedo como temor irán entrelazándose con pequeños atisbos de valentía (que se verá más adelante), en tanto se complejiza y se desenvuelve la relación amorosa entre el militante Frentista y la protagonista.

Este entrecruzamiento de emociones se observa luego de interpelar a la señora de la micro que recriminaba a los jóvenes por no dar el asiento, agregando que solo saben tirar piedras y hacer barricadas:

Entonces no aguanto más y las palabras le salieron a borbotones; mire señora, yo creo que alguien tiene que decir algo en este país, las cosas que están pasando, y no todo está tan bien como dice el gobierno. Además fíjese que en todas partes hay militares como si estuviéramos en guerra, ya no se puede ni dormir con tanto balazo. Mirando a todos lados, la Loca del Frente se asustó al decir eso, porque en realidad nunca se había metido en política, pero el alegato le salió del alma. (...) uno tiene que defender lo que cree justo, se dijo, sorprendiéndose un poco de pensar así. Quizás con un poquito de temor al decidirse a hablar esos temas, más bien defenderlos en público (Lemebel, 2001, p. 59-60).

Este momento de la novela hace carne la célebre consigna de Rosa Luxemburgo: "Quien no se mueve, no siente sus cadenas". Es el movimiento de La Loca, un tanto impulsivo, un tanto reflexivo, lo que la hace paulatinamente empezar a cuestionar e incorporar la rabia y el malestar de la cual tanto hablaba Carlos: "Y por suerte para ella, había llegado Carlos a su vida mostrándole la realidad cruel que rodeaba a los chilenos" (Lemebel, 2001, p. 101). La indiferencia va quedando atrás en la novela, desterrada por un juego romántico entre reflexión y la acción, esta última muchas veces motivada más por el amor por el frentista que por otra cosa, pero que de todas formas le hace pensar y sensibilizarse con la injusticia. 


\section{Valentía}

El artículo de Poma y Gravante (2015) citado anteriormente, señala que, en un grupo de jóvenes de Oaxaca: “...para superar el miedo producido por la violencia que viven todos los días como mujeres, se han auto-organizado en un colectivo que organiza cursos de autodefensa para mujeres de diversos estratos sociales y edades" (p. 21). Luego, los autores agregan que:

Lo que el estudio de la dimensión emocional de la protesta evidencia es que cuando estas emociones son compartidas y manejadas colectivamente, es posible que a través de un trabajo emocional la tristeza o dolor se trasformen en "rebeldía organizada", citando las palabras de los zapatistas. (p. 22)

Lo colectivo se transforma en una herramienta para superar el miedo y proyectar la acción. En Tengo Miedo Torero , esta colectividad se expresa en la relación entre Carlos y la Loca del Frente. Es fruto de esta relación de amor por la cual la Loca se atreve a llevar el valioso paquete de Carlos:

¿Y si lo fuera a dejar yo?, preguntó sugestiva la Loca del Frente. Es delicado, más bien confidencial. Me encanta las películas de espías. Dime dónde es. ¿Lo harías por mí? La loca soltó una honda exclamación: Supieras de lo que soy capaz. (Lemebel, 2001, p. 123)

La potencia de la colectividad para impulsar la valentía se observa también en el encuentro de la Loca del Frente con las mujeres que se manifiestan por sus familiares detenidos desaparecidos:

Era extraño, pero allí, en medio de las señoras, no sentía vergüenza de alzar su voz mariflauta y sumarse al descontento. Es más, una cálida protección le esfumó el miedo cuando las sirenas de las patrullas disolvieron el mitin y ella tuvo que correr. (p.156)

Entonces, la valentía surge desde una dimensión colectiva y la protesta cumple ese doble rol del que hablan De la Maza y Garcés (1985): por un lado, mostrar oposición a las políticas de Estado, pero también reconstruir los lazos colectivos, confrontando así la lógica individualista y atomizada que buscaba implantar la dictadura en la sociedad chilena.

En definitiva, las emociones observadas en la obra permiten dar cuenta de que la experiencia de movilización social contra la Dictadura es mucho más compleja de lo que se representa desde la historia oficial, e incluso desde la Nueva Historia Social. Como en toda movilización social, existieron una serie de entramados emocionales y subjetivos que movilizaron o retuvieron el accionar de los sujetos colectivos en Dictadura. De esta forma, aproximarse a estas dimensiones podría permitir un abordaje más completo de las experiencias históricas, en donde recursos no tradicionales (como las novelas, pero también otros materiales), tienen mucho que entregar para el análisis. 


\section{Conclusiones}

A lo largo de este trabajo se han observado las representaciones acerca del movimiento social contra la dictadura, en la única novela del artista Pedro Lemebel, Tengo Miedo Torero. Se ha puesto énfasis en la descripción sobre las movilización social contra la dictadura, y cómo en ella se integra la dimensión emocional.

Es posible concluir que el autor entrega en su obra una representación del movimiento social cercana a la Nueva Historia Social, ponderando narraciones sobre los sectores populares, la cesantía, la marginalidad, las mujeres, la juventud y la disidencia sexual.

Sin embargo, la narrativa propia del autor, en parte caracterizada como Neobarroco, integra otros elementos a su obra que permiten una visión distinta a la propuesta por las corrientes historiográficas mencionadas: estos elementos refieren principalmente a lo emocional. En ese sentido, la propuesta literaria de Pedro Lemebel no es solamente marginal en relación con el sistema dictatorial, sino que también es periférica (e incluso discriminada) con respecto a las organizaciones de izquierda tradicional, e incluso a organizaciones de corte revolucionario, las cuales "reprodujeron en su interior las concepciones heterosexuales y homofóbicas de la sociedad que esperaban destruir" (Ruiz, 2017, p. 178). La lectura de Lemebel de "Manifiesto (hablo por mi diferencia)", en el año 1986 en un acto organizado por el Partido Comunista, es justamente "una respuesta insolentemente performativa a la homofobia de la izquierda chilena" (Antivilo, 2017, p. 93).

La posición biográfica de Pedro Lemebel, como pobre y maricón, como combatiente político y artístico contra la opresión dictatorial y homofóbica, la convierte en un referente para los movimientos sociales actuales. Difícilmente se puede pensar en la actualidad en algún proyecto transformador de sociedad que no incluya la subjetividad, las emociones, la disidencia sexual, o "esos niños que van a nacer / Con una alita rota / Y yo quiero que vuelen compañero / Que su revolución / Les de un pedazo de cielo rojo / Para que puedan volar" (Lemebel, 2011). En ese sentido, concordamos con Cristian Montes (2020), para quien la obra Tengo Miedo Torero no es solamente una novela postdictatorial, sino que también es una novela política, "en cuanto exterioriza los variados núcleos de significación desde los cuales resiste el poder” (pp. 195-196).

En suma, el análisis de la obra de Lemebel llama a cuestionar la forma en que entendemos nuestra historia colectiva; es una invitación a acercarnos a la emocionalidad de los procesos sociales, no como un dato secundario, sino como una forma "otra" de comprender y estudiar nuestro pasado. Así también, la obra del autor no es solo un "reflejo de su tiempo", sino que trastoca los imaginarios y representaciones que la sociedad, en el tiempo presente, maneja sobre su propia historia e identidad. En la novela, como señala Montes (2020):

la percepción de la crisis del tejido social que sufre el país y las diversas modalidades de violencia a ello asociadas, convive con un deseo de reconstrucción de dicho entramado, a partir de valores que resisten la imposición de fuerza del orden hegemónico. (pp. 196-197) 
De esta forma, una segunda proyección de este trabajo es potenciar la investigación social sobre las representaciones artísticas, ya no solo como imágenes estáticas, sino como procesos que trastocan y conmueven el imaginario colectivo de una sociedad. Tanto las expresiones artísticas como las emociones pueden ser materiales de investigación interesantes para abordar los recientes cambios sociales de nuestro país, así como también para proponer una relectura de nuestra historia.

\section{Referencias}

Aguirre, A. (28 de abril de 2001). Tengo Miedo Torero. El Mercurio. Recuperado de: http://www.bibliotecanacionaldigital.gob.cl/bnd/628/w3-article-212525.htm

Almeida, P. (2020). Movimientos sociales. La estructura de la acción colectiva. Buenos Aires: CLACSO.

Almenara, E. (2016). Escritura, travestismo e izquierda en Pedro Lemebel. Nomadías, 21, 81-96. DOI: $10.5354 / 0719-0905.2016 .42822$

Alvarado-Borgoño, M. (2016). Apuntes sobre el neobarroco: de teorías y metalenguas. Cinta moebio, 57, 330-343.

DOI: http://dx.doi.org/10.4067/S0717-554X2016000300008

Antivilo, J. (2017). Pongo el culo compañero: Izquierda, disidencia sexual y performance. Vínculos, fisuras y rupturas en Chile. Arte y políticas de la identidad, 15, 91-110. https://doi.org/10.6018/284431

Barrera, K. (2016). La Loca en el Frente. Nomadías, 21, 39-58.

Becker, H. (2008). Los mundos del arte. Sociología del trabajo artístico. Buenos Aires: Universidad Nacional de Quilmes.

Bourdieu, P. (1990). El campo literario. Prerrequisitos críticos y principios de método. Criterios, 25-28, 20-42.

Bravo, V. (2012). Neoliberalismo, protesta popular y transición en Chile, 1973-1989. Política y Cultura, 37, 85-112. Recuperado de: https://polcul.xoc.uam.mx/index.php/polcul/article/view/1171

Bravo, V. (2019). Etnografía histórica de la protesta urbana: las jornadas nacionales contra la Dictadura, Santiago de Chile, 1983-1986. Revista Antropologías del Sur, 6(12), 129-148. https://doi.org/10.25074/rantros.v6i12.1547

Calhoun, C., y Wieviorka, M. (2013). Manifiesto por las Ciencias Sociales. Revista Mexicana de Ciencias Políticas y Sociales, 58(217), 29-60. Recuperado de: http://www.revistas.unam.mx/index.php/rmcpys/article/view/42176/38315

Castro, R. (2021). Lemebel, el Neobarroco y la subversión del lenguaje: Tengo Miedo Torero contra el discurso de la transición chilena. $452^{\circ} \mathrm{F}, 24,161-179$. https://doi.org/10.1344/452f.2021.24.11

Da Costa, J. (2020). Reelaborações da ditadura chilena na narrativa de um homossexual: Tengo Miedo Torero de Pedro Lemebel. Raído, 14(35), 92-101.

DOI: $10.30612 /$ raido.v14i35.11256

Da Silva, W. (2012). Fronteras del deseo: melodrama y crítica social en Tengo Miedo Torero, de Pedro Lemebel. Castilla. Estudios de Literatura, 3, 181-204. Recuperado de: https://revistas.uva.es/index.php/castilla/article/view/110 
De la Maza, G., y Garcés, M. (1985). La Explosión de las Mayorías. Protesta Nacional 19831984. Santiago: Educación y Comunicaciones. Recuperado de: http://www.ongeco.cl/multimedia/La-Explosion-de-las-Mayorias.pdf

Donoso, K. (2013). El "apagón cultural" en Chile: políticas culturales y censura en la dictadura de Pinochet 1973-1983. Outros Tempos, 10(16), 104-129. Recuperado de: https://outrostempos.uema.br/index.php/outros_tempos_uema/article/view/285/281

Fry, M. (2020). Los movimientos sociales latinoamericanos. Teorías críticas y debates sobre la formación. Revista de Ciencias Sociales, 33(47), 13-30. http://dx.doi.org/10.26489/rvs.v33i47.1

Garcés, M. (2013). Las luchas urbanas en Chile el último tercio del siglo XX. Trashumante. Revista Americana de Historia Social, 1, 74-95. https://revistas.udea.edu.co/index.php/trashumante/article/view/16567/14375

Garretón, M. (1993). La oposición política y el sistema partidario en el régimen militar chileno. Un proceso de aprendizaje para la transición. En P. Drake e I. Jaksic (Eds.), El difícil camino hacia la democracia en Chile 1982-1990 (pp. 391-454). Santiago: FLACSO.

Garretón, M. (2014). Las ciencias sociales en la trama de Chile y América Latina. Estudios sobre transformaciones sociopolíticas y movimiento social. Santiago: LOM Ediciones.

Grez, S., y Salazar, G. (1999). Manifiesto de Historiadores. Santiago: LOM Ediciones.

Heinich, N. (2002). La sociología del arte. Buenos Aires: Nueva Visión.

Hueso, S. (2013). Camp y Neobarroco en Tengo Miedo Torero de Pedro Lemebel. En M. Soler, y M. Navarrete (Eds.), Del lado de acá. Estudios literarios hispanoamericanos (pp. 397406). Roma: Aracne.

Ímaz, C. (2017). Gitano. Sombra de la memoria viva. Santiago: Carlos Ímaz Gispert. Recuperado de:

https://www.marxists.org/espanol/tematica/guerrilla/chile/fpmr/gitano/gitano-por-carlosimaz.pdf

Jara, I. (2020). ¿Cómo pensar a acción artístico-cultural de la dictadura chilena? Siete cuestiones para su interpretación. Latin American Research Review, 55(2), 338-351. http://doi.org/10.25222/larr.436

Jasper, J. (2013). Las emociones y los movimientos sociales: veinte años de teoría e investigación. Revista Latinoamericana de Estudios sobre Cuerpos, Emociones y Sociedad, 4(10), 46-66. Recuperado de: http://www.relaces.com.ar/index.php/relaces/article/view/240/237

Lagos, R. (2008). Concertación de partidos por la democracia. Quórum. Revista de Pensamiento Iberoamericano, 20, 33-40. Recuperado de: https://ebuah.uah.es/dspace/bitstream/handle/10017/11342/concertaci\%c3\%b3n_lagos_Q UORUM N20.pdf?sequence $=1 \&$ isAllowed $=\mathrm{y}$

Lemebel, P. (2001). Tengo Miedo Torero . Santiago: Seix Barral.

Lemebel, P. (2011). Manifiesto (hablo por mi diferencia). Revista Anales, 7(2), 218-221. DOI: $10.5354 / 0717-8883.2011 .19449$

López, B. (2005). Tengo Miedo Torero, de Pedro Lemebel: ruptura y testimonio. Estudios Filológicos, 40, 121-129. http://dx.doi.org/10.4067/S0071-17132005000100008

Manickam, S. (2010). La sexualidad desafiante frente al dictador en Tengo Miedo Torero. Hispanófila, 159, 39-51. Recuperado de: https://www.jstor.org/stable/43808605

Memoria Chilena. (2018). Tengo Miedo Torero. Recuperado de: http://www.memoriachilena.gob.cl/602/w3-printer-96707.html 
Moles, A. (2011). Principios y virtudes del kitsch. En T. Kulka (Ed.), El kitsch (pp. 49-62). Madrid: Casimiro libros.

Montes, C. (2020). Modalidades de violencia y resistencia política en Tengo Miedo Torero de Pedro Lemebel. En F. Blanco. (Ed.), La vida imitada: narrativa, performance y visualidad en Pedro Lemebel (pp. 177-200). Madrid: Iberoamericana Vervuert.

Neyret, J. P. (2007). Entre acción y actuación: La politización del kitsch en El Beso de la Mujer Araña de Manuel Puig y Tengo Miedo Torero de Pedro Lemebel. Espéculo. Revista de Estudios Literarios, $36 . \quad$ Recuperado de: http://www.ucm.es/info/especulo/numero36/puiglebe.html

Otano, R. (1995). Crónica de la transición. Santiago: LOM Ediciones.

Pérez, C. (2019). Reficcionar la crueldad: teatralización y travestismo en Tengo Miedo Torero de Pedro Lemebel. Revista Chilena de Literatura, 99, 303-316. Recuperado de: https://revistaliteratura.uchile.cl/index.php/RCL/article/view/53027/55606

Pinto, D. (2016). Secretos viscerales: transgresión y cuerpo en Tengo Miedo Torero de Pedro Lemebel. Textos Hibridos, 5, 93-108.

DOI: $10.15691 /$ textoshibridos.v5i1.63

Poma, A., y Gravante, T. (2015). Las emociones como arena de la lucha política. Incorporando la dimensión emocional al estudio de la protesta y los movimientos sociales. Ciudadanía Activa, 3(4), 17-44. Recuperado de: https://www.academia.edu/20843805/Las_emociones_como_arena_de_la_lucha_pol\%C3 \%ADtica_Incorporando_la_dimensi\%C3\%B3n_emocional_al_estudio_de_la_protesta_y los movimientos sociales

Poma, A., y Gravante, T. (2017). Emociones, protesta y acción colectiva: estado del arte y avances. Aposta. Revista de Ciencias Sociales, 74, 32-62. Recuperado de: http://www.apostadigital.com/revistav3/hemeroteca/apoma.pdf

Rovira, C. (2007). Chile: transición pactada y débil autodeterminación colectiva de la sociedad. Revista Mexicana de Sociología, 69(2), 343-372. DOI: http://dx.doi.org/10.22201/iis.01882503p.2007.002.6095

Ruiz, C. (2019). El tiempo de la dictadura en Tengo Miedo Torero de Pedro Lemebel. Pizarrón Latinoamericano, 10(8), 73-88.

Ruiz, M. (2017). Mandatos militantes, vida cotidiana y subjetividad revolucionaria en el Movimiento de Izquierda Revolucionaria de Chile (1965-1975). Revista Austral de Ciencias Sociales, 28, 163-182.

DOI: https://doi.org/10.4206/rev.austral.cienc.soc.2015.n28-09

Sandoval, J. (2018). Sospechas maricas de la cueca democrática: arte, memoria, y futuro en "Las Yeguas del Apocalipsis" (1988-1993). Estudios de Filosofía, 58, 9-39.

DOI: https://doi.org/10.17533/udea.ef.n58a02

Sapiro, G. (2016). La sociología de la literatura. Buenos Aires: Fondo de Cultura Económica.

Sarduy, S. (1974). El barroco. Buenos Aires: Sudamericana.

Sontag, S. (2005). Contra la interpretación. Buenos Aires: Alfaguara.

Sossa, A. (2013). Una aproximación desde la sociología del cuerpo a los movimientos sociales. Revista Latinoamericana de Estudios sobre Cuerpos, Emociones y Sociedad, 5(13), 9-20. Recuperado de: http://www.relaces.com.ar/index.php/relaces/article/view/36/35

Trejo, A., y Waldman, G. (2018). Pasaporte sellado. Cruzando las fronteras entre ciencias sociales y literatura. Ciudad de México: Universidad Autónoma de México. 
Valdivia, V. (2016). La Unión Demócrata Independiente (UDI): Un caso de conservadurismo modernizador en Chile. Nuevo mundo, mundos nuevos, Coloquios.

DOI: https://doi.org/10.4000/nuevomundo.68811

Vega, C. (2013). El Colectivo de Acciones de Arte y su resistencia artística contra la dictadura chilena (1979-1985). Revista Divergencia, 2(3), 37-48. Recuperado de: http://www.revistadivergencia.cl/wpcontent/uploads/2018/11/02_el_colectivo_de_accion es de arte.pdf

Venegas, H. (2009). Trayectoria del Partido Comunista de Chile. De la crisis de la Unidad Popular a la política de rebelión popular de masas. UNIVERSUM, 24(2), 262-293. http://dx.doi.org/10.4067/S0718-23762009000200013

Ward, M. (2016). (Re)escribiendo la heteronormatividad en tiempos de Pinochet. Textos Híbridos, 5, 128-155.

DOI: 10.15691/textoshibridos.v5i1.65

Yeguas del Apocalipsis. (2018). Yeguas del Apocalipsis. Recuperado de: http://www.yeguasdelapocalipsis.cl/biografia/ 